\title{
LA FÁBULA ESÓPICA: TRANSMISIÓN Y DIFUSIÓN EN LA CULTURA SEFARDÍ CONTEMPORÁNEA
}

\author{
MARÍA SÁNCHEZ PÉREZ \\ Universidad de Salamanca
}

\begin{abstract}
RESUMEN
A pesar de que el cuento popular es un género muy conocido y apreciado por los sefardíes, apenas se han conservado relatos sobre animales o fábulas en la tradición moderna y contemporánea. Por este motivo, es bastante destacado que hayamos encontrado algunas fábulas entre las páginas de algunos periódicos sefardíes, publicados entre finales del siglo XIX y principios del XX. En el presente trabajo se editan y estudian varias fábulas esópicas que se incluyeron en los siguientes periódicos en judeoespañol: El Amigo de la Famiya (Constantinopla, 1881-1886), La Époka Literaria (Salónica, 1908) y El Rizón (Salónica, 1926-1939).
\end{abstract}

PALABRAS CLAVE: judeoespañol, prensa, fábula, sefardíes.

\begin{abstract}
Despite that folktale is a very well known and appreciated genre by the Sephardim people, barely have been preserved some animal tales or fables in modern and contemporary tradition. For this reason it is noteworthy that we have found some fables among the pages of some Sephardic newspapers which had been published between the late nineteenth century and early twentieth century. In this work we edited and studied several aesopic fables that were included in the following newspapers in djudeo-espanyol (ladino): El Amigo de la Famiya (Constantinople 1881-1886), La Époka Literaria (Thessaloniki, 1908) El Rizón (Thessaloniki, 1926-1939).
\end{abstract}

KEY WORDS: Judeo-Spanish, press, fable, Sephardic.

\section{INTRODUCCIÓN}

La fábula esópica es bien conocida a través de las cuantiosas colecciones y traducciones que se han realizado desde sus remotos orígenes hasta la actualidad. Transmitidas oralmente o por escrito, se difundieron en diversas lenguas y en diferente forma: prosa y verso. Su carácter entretenido, a la par que instructivo y didáctico, ha hecho que el género haya gozado de enorme popularidad desde antiguo. Cierto es, no obstante, que ha habido diferentes épocas y momentos en las que el gusto por este tipo de narraciones caló de forma más o menos exitosa.

En el caso de la literatura sefardí, el cuento popular ha sido, desde siempre, uno de los géneros más castizos de su cultura. Esas narraciones se transmitieron oralmente Recibido 14-X-2015. Aceptado: 23-XI-2015 
durante sucesivas generaciones, sirvieron para muchos aspectos y situaciones de la vida y, hoy en día, sigue siendo un género muy vivo en la tradición judeoespañola. La temática de esos cuentos es muy variada, aunque los más típicamente sefardíes son los que tienen como protagonistas o bien a Djohá ${ }^{1} \mathrm{o}$ bien a rabinos y personajes bíblicos. Sin embargo, cabe destacar la escasez de cuentos cuyos protagonistas sean animales. ${ }^{2}$ Con los datos que conocemos actualmente, parece que las fábulas no abundaron en la cuentística sefardí $y$, como veremos, todo parece indicar que las que se publicaron en las páginas de algunos periódicos -entre finales del siglo XIX y principios del $x x$ - se tomaron de fuentes occidentales. ${ }^{3}$ Para este estudio nos basaremos en varias fábulas publicadas en tres periódicos sefardíes": El Amigo de la Famiya (Constantinopla, 1881-1886), La Époka Literaria (Salónica, 1908) y El Rizón (Salónica, 1926-1939). ${ }^{5}$

\footnotetext{
1 Dhojá (Goha, Djuha, Giufà, J'ha, etc.) es un personaje bien conocido en el cuento popular oriental desde la Alta Edad Media- y está muy presente también en la tradición judeoespañola. Véase Clara M. ${ }^{a}$ Thomas de Antonio, «Ŷuhāa, un personaje popular en el Magreb y en todo el mundo árabe», Al-Andalus Magreb 1 (1993), pp.187-223.

2 Julio Camarena («Cuento español, cuento sefardí: paseo entre dos mundos», en Judith Targarona y Ángel Sáenz-Badillos, eds., Jewish Studies at the Turn of the 20th Century, Leiden, Boston y Colonia, Brill, 1999, vol. II, pp. 485-490) sustentaba esta afirmación basándose en lo ya expuesto por Paloma Díaz-Mas, Los sefardíes. Historia, lengua y cultura, Barcelona, Riopiedras, 2006 (4 ${ }^{\mathrm{a}} \mathrm{ed}$.), especialmente en p. 172.
}

3 En otro lugar analizamos también una de las escasas fábulas documentadas en la tradición sefardí: María Sánchez-Pérez, «Tradición y modernidad: la fábula La rapoza se va al hadjilik en el periódico sefardí El Konsejero (Salónica, 1913)», Estudios Humanísticos. Filología 35, pp. 109-120. Sin embargo, en aquella ocasión todo parece indicar que procedía de una narración popular árabe y no de la tradición occidental. En nota al pie 6 indicamos el sistema de transcripción utilizado y al final del trabajo incluimos un glosario aclarando aquellos términos que puedan ofrecer alguna dificultad de comprensión al lector.

4 Este trabajo es producto del Proyecto de investigación FF2012-31625 «Los sefardíes ante sí mismos y sus relaciones con España III. Hacia la recuperación de un patrimonio cultural en peligro» del Ministerio de Economía y Competitividad de España.

5 Dentro del conjunto de la literatura sefardí, el periodismo se considera uno de los géneros adoptados, junto al teatro, la poesía de autor y la narrativa, puesto que carecían de tradición en la literatura judeoespañola y comenzaron a cultivarse a mediados del siglo XIX en un afán por imitar a las literaturas occidentales, frente a ellos estarían los conocidos como géneros tradicionales que engloban el refranero, el romancero, el cancionero y los cuentos populares. Son cientos los periódicos sefardíes que conservamos desde mediados del siglo xIx hasta la Segunda Guerra Mundial. La mayor parte de ellos -como los que veremos aquí- se imprimieron en judeoespañol aljamiado, esto es, judeoespañol escrito con caracteres hebreos. No obstante, también existieron periódicos sefardíes escritos en caracteres latinos e incluso en otras lenguas, dándose el caso de publicaciones en varios idiomas: el periódico Salonik (Salónica, 1869) llegó contener partes en «judeoespañol, búlgaro, turco y griego» (Iacob M. Hassán, «El estudio del periodismo sefardí», Sefarad 26, 1966, pp. 229-235; cita, pp. 231). Por lo tanto, se utilizaron diferentes grafías y alfabetos. Respecto a los contenidos, fueron muy variados. Hubo periódicos de información general, de divulgación científica, histórica, etc. También de diferente signo político -sionistas, socialistas, etc.-. Un número bastante elevado lo forman publicaciones de pasatiempo, ya fueran culturales y literarias o de tono humorístico, satírico y festivos. El Amigo de la Famiya y La Époka Literaria responden más a publicaciones destinadas a la divulgación de contenidos fundamentalmente literarios y enciclopédicos, mientras que El Rizón se encuadra dentro de la prensa festiva y de pasatiempo. 


\section{El Amigo de la Famiya (Constantinopla, 1881-1886) ${ }^{6}$}

Uno de los periodistas más activos de Constantinopla fue David Fresko.7 A él se deben algunos de los periódicos más longevos de la ciudad como El Tiempo «periódiko israelita polítiko, literario, komersial y finansiero», fundado en 1871 y que vio la luz hasta 1930, fecha en la que Fresko abandonó el periodismo, muriendo tres años después. ${ }^{8}$ Publicó, además, varios suplementos de El Tiempo: El Sol «revista sientífika i literaria» (1877-1878), El Amigo de la Famiya «revista periódica ilustrada» (1881-1886) y El Instruktor «revista sientífika i literaria» (1888-1889). ${ }^{9}$ Nos interesan ahora algunas de las fábulas que aparecieron en el segundo suplemento: El Amigo de la Famiya. ${ }^{10}$

De carácter literario y enciclopédico, este periódico semanal publicó durante un lustro contenidos muy diversos. Como muestra, veamos una parte de su declaración de intenciones:

El Amigo de la Famiya tendrá este punto. Él será un dulse pasatiempo: rakontará unos kuentos kuriozos i savrozos de la istoria del mundo, munchas maravías de las ovras del Kreador, unos viajes por las kuatro partes del mundo, reseftas por algunas hazinidades o aksidentes (kazas), la manera de rejir en el bivir, la manera de engrandeser las kriaturas, refranes, enigmas (kidot, bilmedjekes), i en vezes mostrará también las modas de_los vestidos kon sus formas i sus figuras. En kurto, avlará de todo lo_ke puede interesar ala famiya, tanto a los chikos komo a_los grandes [El Amigo de la Famiya, n. ${ }^{\circ}$, pág. 1, col. a]. ${ }^{11}$

\footnotetext{
6 Dado que los textos que ofrecemos al lector son transcripciones de originales aljamiados, señalamos a continuación el sistema de transcripción utilizado y las equivalencias gráfico-fonéticas: $b$ bilabial oclusiva sonora $/ \mathrm{b} / ; v$ bilabial fricativa sonora $/ \mathrm{b} / ; d j$ prepalatal africada sonora $/ \hat{y} / ; h$ uvular fricativa sorda $/ i / ; j$ prepalatal fricativa sonora $/ \check{z} / ;$ ly lateral palatal $/ \lambda /$, que la mayor parte de las veces se realiza en judeoespañol como /y/; ny nasal palatal / $\mathrm{y} / ;$ s alveolar fricativa sorda $/ \mathrm{s} / ; z$ alveolar fricativa sonora /z/; sh prepalatal fricativa sorda /š/; ts alveolar africada sorda / $\hat{\mathrm{s}}$ /. Transcribimos en VeRSALITAS las partes que están escritas en letra merubá en el original. Puntuamos y acentuamos el texto.
}

7 David Fresko (1853-1933) periodista bien conocido en Constantinopla y de carácter un tanto polémico, de hecho sus controversias con las autoridades rabínicas hicieron que fuese excomulgado en 1887. Tenía una ideología antisionista y fue uno de los intelectuales que estaba en contra del uso del judeoespañol, lo que no le impidió que publicase un número no poco elevado de publicaciones en esa lengua ni que tradujese al judeoespañol numerosas obras de la literatura hebrea, francesa e inglesa como, por ejemplo, Amor de Siyón, Miguel Strogoff, Los hijos del Capitán Grant o Del fondo de la noche. Algunos trabajos relacionados con su obra pueden verse en: Amor Ayala, «'La instruksión es el más ermozo afeite por la mujer'. Una conferencia de David Fresco sobre la nueva mujer sefardí (Estambul, 1929)», Sefárdica 17 (2008), pp. 144-155; Aitor García Moreno, «Glosas frescas en La hermośa Ḥulda de España (Jerusalén, 1910)», Paloma Díaz-Mas y María Sánchez-Pérez, eds., Los sefardíes ante los retos del mundo contemporáneo. Identidad y mentalidades, Madrid, CSIC, 2010, pp. 75-85; y Michael Studemund-Halévy y Gaëlle Collin (2013), «The Wondrous Story of Diego de Aguilar», en Michael Studemund-Halévy, Christian Liebl e Ivana Vučina Simović, eds., Sefarad an der Donau. Lengua y literatura de los sefardies en tierras de los Habsburgo, Barcelona, Tirocinio, 2013, pp. 239-247. Para más datos véase Sefardiweb del CSIC, disponible en http:/ / sefardiweb.com/node/ 251 [consultado 24-04-2015].

8 Elena Romero, La creación literaria en lengua sefardí, Madrid, MAPFRE, 1992, p. 182.

9 Datos tomados de Sefardiweb del CSIC, disponible en http://sefardiweb.com/node/251 [consultado 24-04-2015].

10 La fuente de procedencia de los textos de los periódicos que aquí manejamos son microfilmes de la Jewish National and University Library de Jerusalén, hoy Biblioteca Nacional de Israel.

11 Cristina Martínez-Gálvez, El periodismo sefardí ante su público. Tesis Doctoral. Universidad de Valen- 
Entre sus páginas se encuentran, por tanto, artículos de tipo histórico, sobre la naturaleza, el cuerpo humano, remedios caseros y naturales para muchos y diversos aspectos, etc. No extraña, por tanto, que se publicaran fábulas como las siguientes. ${ }^{12}$

\subsection{La fábula «El cordero y el lobo»}

Apareció en el número 35 (15/12/1881). El texto reza así:

\section{EL DERECHO DEL MÁS FUERTE \\ Imitasión del poeta fransez «La Fonten» \\ La razón del más fuerte es siempre la valiente, según lo vamos a provar inmediatamente.}

Un povre kodreriko

abashó a un aroiko

por bever aguita freska,

ke tenía la boka seka.

Un lovo muy ambriento,

ke atinó al povreto,

kon un salto a él anda

$\mathrm{i}$ «ké aze» le demanda.

-Bevo -dize el neshgueliko ${ }^{13}$ agua freska del choriko.

-Kuando beves agua, ¿saves

ke de ariva abasho azes

i turvando la agua entera

a mi boka viene tiera?

-Alteza, ¿ké kulpo lyo

si la agua se turvió?

Dies metros leshos me ves

de aonde tu agua beves.

I la agua ke de ti sovra

i ke está turvia aora,

esta kon muncho apreto

bevo lyo el povreto.

-No te dishe, endagora,

ke tú turvas la agua aora, ma oi aze djusto un anyo

25

topé la agua komo kanyo.

-¡Alteza, kedo enkantado

de olyr ke e turvado

5 antes de aver nasido

este aroyo engrandesido!

-Si tú propio no eres,

te diré la verdad si keres:

tu ermano paresía,

10 ke entonses dies mezes tenía.

$¡ \mathrm{O}$, kuánto esto me desplaze!

I por esto gran plazer me aze

de areglar este kuenteziko,

ke me kedó de tu ermaniko.

15 -Lyo tenía un ermaniko,

ma era de mí más chiko

$i$ lo vide al desgrasiado

en la karnisería (kasap) enkolgado.

-Si no era tu ermano,

20

sería de ti algún serkano.

Diziendo el lovo esto

afera al kodrero presto,

lo despedasa sin piedad,

esta es la pura verdad.

[El Amigo de la Famiya, p. 280, cols. b y c]

cia, 2012, p. 31 de la edición de los periódicos. Disponible en http:/ / roderic.uv.es/handle/10550/24872 [consultado 25-02-2015].

$12 \mathrm{Al}$ ser un periódico longevo y extenso no hemos realizado un vaciado exhaustivo de contenidos para comprobar si se publicaron más fábulas, pero es muy probable.

${ }^{13}$ Probablemente por 'nezgueliko', ya que procedería del antiguo español 'nezuelo' (diminutivo de 'ne- 
La fábula está basada en la oposición de dos personajes antitéticos (lobo = fuerte vs. cordero = débil) y «la mentira del lobo vence sobre la verdad del cordero; la mentira, en definitiva, desbanca a la verdad» $\mathrm{y}$, en este caso:

el modelo esópico reconoce que el lobo ha «perdido» por no encontrar pretextos justificados para comerse al cordero y debe, por tanto, modificar su táctica; Fedro, en cambio, elimina la admisión de la derrota del lobo y pasa rápidamente al ataque del mismo, condenándolo como iniustus. ${ }^{14}$

La fábula es bien conocida desde antiguo y es probable que, tal y como se expresa en el periódico, fuese tomada de alguna colección de La Fontaine -aspecto sobre el que volveremos más adelante.

\subsection{La fábula «La gallina de los huevos de oro»}

Se publicó en el número 146 de El Amigo de la Famiya (7/4/1884):

LA GAÍNA A UEVOS DE ORO

El eskaso piedre todo keriendo todo ganar por provar esto la fábula de Ezop vo kontar: Una gaína, tenía uno, ke ponía uevos de oro; le paresió ke en su vientre tenía un trezoro, la degolyó, la avrió i_la topó, el negro, semejante a_las otras ke tenía en el gainero kedando ansí manko también de_lo más presiozo de su bien. Ermoza leksión para los eskasos ke en nuestros días no son ralos keriendo azer muy presto fortuna piedren lo ke tienen todo de una.

[El Amigo de la Famiya, p. 48, cols. b y c]

En el caso español, esta fábula se popularizó aún más a partir del siglo XVIII con la obra de Félix M. Samaniego, cuya etapa de madurez como escritor coincide con el mayor auge y esplendor de la Ilustración, periodo en el que buena parte de la literatura se desarrolla con un fin utilitarista, de acuerdo con los postulados dieciochescos. Ese fin con el que Samaniego publica sus fábulas no dista mucho del que tendrían los directores y editores de estos periódicos sefardíes, como veremos después. Siguiendo

cio') y que viene a significar 'pobrecito', tal y como lo recogemos en el glosario. Así, por ejemplo, aparece en La Celestina: ¡Neciuelo, loquito, angelico, perlica, simplezico! (Primer Auto, Cena 10. ${ }^{\mathrm{a}}$ ), (Fernando de Rojas, La Celestina, edición de Peter E. Russel, Madrid, Castalia, 1993, p. 253).

14 Fábulas. Fedro y Aviano, Manuel Mañas Núñez, ed. Madrid, Akal/clásica, 1998, p. 42. 
la edición a esos textos realizada por Alfonso I. Sotelo, en el caso de esta fábula se indica que Samaniego «adapta La Fontaine». ${ }^{15}$

\section{La ÉPOKa Literaria (SALÓNICA, 1908)}

La Époka Literaria fue un suplemento de otro periódico titulado La Époka, que fue uno de los más longevos de Salónica, ya que se publicó desde 1875 hasta 1911. ${ }^{16}$ Sin embargo, del primero únicamente conservamos en la actualidad -que sepamoslos números 1, 2, 3, 5 y 7, todos ellos publicados entre mayo y junio de $1908 .{ }^{17} \mathrm{El}$ fundador de ambos periódicos fue Sa'adi Haleví, periodista e impresor muy conocido en Salónica: ${ }^{18}$

Importante papel en la prensa de Salónica desempeñó la familia Haleví. El patriarca y famoso coplero Sa'adi Haleví fundó en 1875 La Época, «revista política, comercial y literaria», de talante liberal y uno de los más importantes y longevos periódicos de la ciudad [...]. En La Época trabajó también Eliyahu Šem-Tob Arditti, que fue director del suplemento La Época Literaria así como de la nueva serie del periódico iniciada en $1908 .^{19}$

Así pues, en 1908, Sa'adi Haleví -como propietario y colaborador- junto con Eliyahu Sem-Tob Arditti -redactor administrador y colaborador también- comenzaron a publicar La Époka Literaria. En el primer número ya se afirmaba que el periódico «puvlikará enigmas i sharadas / kuentos, novelas, romansos, poezías, / munchas verdades i pokas fantazías» (La Époka Literaria, n. ${ }^{\circ} 1$, p. 2 , col. b) y en el segundo aclaraba el fin de todos estos contenidos:

Mos vamos esforsar de introdusir entre muestras famiyas el gusto de_las lekturas sanas, en mizmo tiempo agradavles ke provechozas. No vamos azer un djornal de informasiones polítikas ni komersiales, ma una puvlikasión esklusivamente literaria, ke interese a todos i pueda ser metida entre todas las manos (La Époka Literaria, n. ${ }^{\circ} 2$, p. 1 , col. a). ${ }^{20}$

15 Félix M. Samaniego, Fábulas, Alfonso I. Sotelo, ed., Madrid: Cátedra, 2003, p. 331, n. 7.

16 Para este periódico y otro titulado El Avenir, véase Yvette Bürki, «La Época y El Avenir. Dos periódicos: dos discursos en contraste», en Paloma Díaz-Mas y María Sánchez-Pérez, eds., Los sefardíes ante los retos del mundo contemporáneo. Identidad y mentalidades, Madrid, CSIC, 2010, pp. 159-170.

17 No hay que olvidar, de todas formas, que La Époka Literaria de 1908 es el segundo intento de publicar ese fascículo literario del periódico La Époka, ya que la primera tentativa se realizó, bajo el mismo título y los mismos responsables, en 1906. Para más datos sobre este aspecto véase se puede incluir ya la referencia completa: Cristina Martínez-Gálvez y María Sánchez-Pérez (2015), «Adaptación al medio: cambios de proyectos iniciales en la prensa sefardí otomana», Historia y comunicación social 20, pp. 67-87.

18 Sa'adi Haleví (¿-1908?) fue un periodista, impresor y activo participante de la comunidad de Salónica. Fue también compositor e impresor de coplas sefardíes, tanto de contenido noticiero como satírico o relacionado con la celebración de festividades litúrgicas. Pueden verse más datos en Sefardiweb del CSIC, disponible en http:/ /www.proyectos.cchs.csic.es/sefardiweb/node/266) [consultado 27-02-2015].

19 Elena Romero, La creación literaria..., p. 184.

${ }^{20}$ Cristina Martínez-Gálvez, El periodismo... p. 83 de la edición de los periódicos. 
Quedaclaro, por tanto, que si los contenidos de LaÉpoka eran, fundamentalmente, políticos y comerciales, su suplemento se funda para ofrecer al lector sefardí asuntos puramente literarios y enciclopédicos. No es de extrañar, por tanto, que se incluyesen fábulas como las siguientes.

\subsection{La fábula «El leopardo y las monas»}

Se publicó en el segundo número de La Époka Literaria (31/05/1908):

El LEOPARDO I LA MONA (maimona)

No a pares, a dozenas enkontrava las monas en la shara, kuando kasava, el leopardo; apena ke lo vian, todas koriendo al árvol se suvían. El leopardo, animal astusiozo -por esto lo yamavan «el pasensiozo»-, se mostrava komo si fuese ya muerto, ke todas las monas lo kreían sierto. Pares a pares, alegres, djugetonas, del leopardo se acerkan las monas: la una lo palpa, la otra lo toka, una otra por guelerlo se aboka, otra grita: «iNo vos detengash un punto! ¡Kored todas a djugar kon el difunto!». Esta sovre él su kavesa arima, akelya, por djugar, se move ensima.

5 Koren, saltan, bailan, kedan abatidas. Muestro leopardo siente las latidas. Luego, viendo ke la ora es propisa, sin pedrer un punto i kon mucha prisa afera la una, modre la otra,

10 mata, despedasa a_la ke enkontra. Mata por matar, no por ke tiene ambre. Mata asta ke aze un río de sangre.

MORAL:

Del enemigo klaro ya me guadro yo, del enkuvierto guadrame tú, jo, Dio!

S.S. [La Époka Literaria, n. ${ }^{\circ}$ 2, p. 12, col. a]

Al igual que ocurría con el caso de La gallina de los huevos de oro esta fábula es también «una creación a partir de La Fontaine». ${ }^{21}$

\subsection{La fábula «El asno y el cerdo»}

Apareció en el número 7 (5/7/1908):

EL AZNO I EL PUERKO

Un azno de el puerko era selozo, lo konsiderava por animal venturozo.

-Yo -dezía- travajo i komo paja, él kome farina i no travaja; todos lo karisan, le ofren regalos,

${ }^{21}$ Félix M. Samaniego, Fábulas..., p. 181, n. 17. 
a_mí kada día me harvan kon palos;

fin ke muchas vezes dezeo la muerte.

Ansí él se lamentava de su suerte.

Supeto el patrón kon la gizandera

entran al kortijo kon una kaldera,

tres, kuatro espetos i un buen kuchío

al puerko aferan, él echa un chío.

El patrón lo korta, la tripa le avre,

keda estirado echo un kadavre.

-Si es para esto ke les dan regalos

-disho muestro azno-, más valen los palos

i todas las penas de mi triste suerte,

ke de los regalos i después la muerte.

S. S. [La Époka Literaria, n. ${ }^{\circ}$ 7, p. 3, cols. a y b.]

Con esta fábula abría precisamente Samaniego su «Libro Primero» y Alfonso I. Sotelo -siguiendo la clasificación estipulada por Rodríguez Adrados ${ }^{22}$ - anota lo siguiente:

Samaniego parece estar cerca de M 55. Asinus et porcus, pág. 431: «El asno, que envidia la vida del cerdo, se finge enfermo y es cebado y engorda. Pero cuando matan al cerdo, se asusta y vuelve a su vida anterior» [...]. Gracián cita unos versos de Lope de Vega con el mismo tema (Agudeza y Arte de Ingenio, Discurso LV). Jareño [...] localiza el argumento en Con su pan se lo coma, Acto II de Lope de Vega y en Tirso de Molina, Adversa fortuna de D. Álvaro de Luna, II, $4 .{ }^{23}$

La fábula, por tanto, era bien conocida en la Península antes incluso de que Samaniego la incluyera entre sus textos.

Por otro lado, cabe destacar que las dos fábulas aparecidas en La Époka Literaria aparecen firmadas por S.S. Todo parece indicar que tras esas siglas se esconde o bien el propio director de la publicación: Sa'adi (Semuel) Haleví o bien el poeta Selomo Salem, quien había refundido en verso judeoespañol las fábulas de La Fontaine. ${ }^{24}$ Se trataría de traducciones o refundiciones de esas fábulas, escritas originariamente en otra lengua -volveremos sobre este aspecto más adelante-. Haleví fue un ferviente defensor del progreso y la occidentalización, de ahí que cobre sentido que en una publicación como la suya se incluyesen estas fábulas, género didáctico por excelencia $\mathrm{y}$, por ende, destinado a enseñar e instruir a sus correligionarios sefardíes. ${ }^{25}$

22 Francisco Rodríguez Adrados, Historia de la fábula clásica, 3 tomos, 4 vols., Madrid, Universidad Complutense, 1979-1987.

${ }_{23}$ Félix M. Samaniego, Fábulas..., p. 163, n. 5.

24 Paloma Díaz-Mas, Los sefardíes..., p. 210.

25 Sa'adi (Semuel) Haleví escribió su autobiografía, que puede verse en judeoespañol e inglés en Aron Rodrigue y Sarah Abrevaya Stein, A Jewish Voice from Ottoman Salonica: The Ladino Memoir of Sa'adi Besa- 
El precepto horaciano de deleitar enseñando cumpliría aquí plenamente su función y las fábulas podrían estar destinadas como lectura entretenida y provechosa para todos los que leyesen su periódico. Se entiende así la declaración de intenciones que aparecía en La Époka Literaria y que citamos más arriba: «lekturas sanas, en mizmo tiempo agradavles ke provechozas. [...] una puvlikasión esklusivamente literaria, ke interese a todos i pueda ser metida entre todas las manos» (La Époka Literaria, n. ${ }^{\circ}$ 2, p. 1, col. a).

Es más, Sa'adi Haleví, en esa declaración de intenciones, iba más allá:

Otro un projeto kontamos realizar: akel de publikar, asta muy poko tiempo, un suplemento destinado a_los elevos de nuestras eskolas. Kale kaminar kon el progreso; dunke, es muy djusto de azer i akí en favor de nuestros ijikos lo_ke se aze por eyos en las grandes sivdades evropeas, ande numerozas puvlikasiones de una utilidad inkontestavle les son konsacradas (La Époka Literaria, n. ${ }^{\circ}$ 2, p. 1, col. a). ${ }^{26}$

Queda claro, por tanto, que su deseo de educación, progreso y occidentalización -especialmente de influencia francesa- debe estar destinado a todos: adultos y niños.

\section{EL RIZÓN (SALÓNICA, 1926-1939)}

El Rizón fue también uno de los periódicos más longevos publicados en Salónica. Tras la revolución de los Jóvenes Turcos (1908) y el fin de la censura, vieron la luz muchas publicaciones como esta, de contenido humorístico y burlón. Su fundador fue Moíz M. Asael, periodista salonicense de la primera mitad del siglo xx, quien dirigió el periódico entre 1926 y $1927 .{ }^{27}$ Se trataba de una revista semanal que constaba normalmente de cuatro páginas. El carácter chistoso y socarrón se apreciaba ya desde la misma portada, cuya ilustración de cabecera la formaban dos cabezas de payasos. ${ }^{28}$ El subtítulo de la publicación tampoco dejaba lugar a dudas con respecto a su naturaleza: «Djornal de burla, shaká i ironía, ke aparese viernes antes de medio día». Este aspecto es destacable al tratarse de un periódico sefardí, ya que esta prensa

lel a-Levi, Standford, Standford University Press, 2012. Presentan, además, un panorama de la sociedad salonicense entre finales del siglo XIX y principios del xx.

26 Ambas citas de Cristina Martínez-Gálvez, El peridodismo..., p. 83 de la edición de textos.

27 Pueden verse algunos datos más sobre él en la página de Sefardiweb del CSIC, disponible en: http://sefardiweb.com/node/42 [consultado el 30-03-2015].

28 «A partir de esa fase inicial, El Riśón va evolucionando a lo largo de los años siguientes por varias etapas que se caracterizan, entre otras cosas, por pequeños cambios en el diseño, la tipografía y el subtítulo. La mayoría de los cambios son el producto de gustos personales de los diferentes directores [...] Bastante diferente hallamos El Riśón a partir del año 1930, cuando por primera vez aparece el título decorado con flores, elemento que encontramos, aunque no de continuo, hasta 1936», en Sandra Schlumpf, «Tradición judía y actualidad social en cuatro artículos publicados en El Riśón de Salónica», en Paloma Díaz-Mas y María Sánchez-Pérez, eds., Los sefardíes ante los retos del mundo contemporáneo. Identidad y mentalidades, Madrid, CSIC, 2010, pp. 183-192, cita 185. 
de pasatiempo servía para entretener al lector y, al mismo tiempo, proporcionarle lectura para el descanso sabático. ${ }^{29}$ Este hecho es ya de por sí particular, ya que en el tradicional mundo sefardí las lecturas apropiadas para el shabat eran las religiosas -así como el descanso y la oración-; no obstante, la influencia de Occidente y la paulatina relajación de ciertas costumbres llevaron a que los sefardíes se distrajesen durante su día festivo de la semana con lecturas cada vez más diversas. ${ }^{30}$

\subsection{La fábula «La cigarra y la hormiga»}

Se publicó en el primer número de El Rizón (9/7/1926):

\section{LAS KONSEJAS DE_LA FONTEN}

Fin agora las konsejas de_la Fonten tuvieron sido muy pokas trezladadas en proz o en poezía de una manera inkompleta. Prometemos de dar una kada semana textualmente i por número de orden de_las obras de la Fonten a_la intensión de_ los chikos lektores elevos de eskola afin ke las entiendan a fondo las konsejas del imortal poeta.

Por esta semana la prima:

LA CHICHIGALIA I LA FORMIGA

La chichigalia aviendo kantado

el enverano entero engleneado, kuando el aver ${ }^{31}$ aviendo soplado

vido ke en su granero asolapado

non aviendo un graniko

mizmo un chiko guzaniko.

Se fue ande su vezina la formiga

ke le emprestara una miga;

la formiga non es emprestadera, por kontra se izo demandadera:

-¿Ke azías tú en el enverano?

- Kantava en un árvol serkano.

- A, si kantavas a_la buena ora, va bailar bueno agora.

LA Fontaine

[El Rizón, n. ${ }^{\text {1 } 1, ~ p . ~ 2, ~ c o l . ~ d] ~}$

\footnotetext{
29 Sobre la prensa de pasatiempo en Salónica, puede verse María Sánchez-Pérez, Prensa sefardí de pasatiempo en Salónica: un «Konsejero» (1913) y dos «Martíos» (1914 y 1927), Barcelona, Tirocinio, 2014.

$30 \mathrm{Al}$ igual que señalamos con El Amigo de la Famiya, al ser un periódico longevo y extenso no hemos realizado un vaciado exhaustivo de contenidos para comprobar si se publicaron más fábulas en él. La que ahora analizamos se publicó en el primer número del periódico y en el texto introductorio que acompañaba a la fábula se anunciaba que se publicaría una cada semana -como veremos a continuación en la transcripción y edición del texto- y, sin embargo, hemos rastreado los primeros números y no hemos encontrado más contenidos de esta índole.

31 En el original parece que encontramos una errata tipográfica, ya que aparece escrito en grafía hebrea: וריא, con una especie de comilla intercalada, después de la 'yod'.
} 
La fábula de «La cigarra y la hormiga» es quizá hoy en día una de las más populares en castellano, debido a su amplia divulgación. Fue publicada también por Samaniego, quien parece seguir de nuevo en su recreación del texto a «La Fontaine, I, 1, La Cigale et la Fourmi». ${ }^{32}$

En el caso de El Rizón no hay duda de que el texto está tomado del escritor francés, pues así aparece expresamente citado, al igual que ocurría con la primera fábula de $E l$ Amigo de la Famiya y frente a lo que veíamos en La Époka Literaria, donde todo parece indicar que era el director del periódico quien traducía, refundía o reelaboraba esas fábulas.

Por último, antes de pasar a las conclusiones, cabe señalar que, aunque El Rizón fuese una publicación de carácter humorístico y burlón, no debe sorprendernos que se incluyesen contenidos de esta índole, de tono grave e instructivo, como las fábulas, y muy lejos, por tanto, del espíritu festivo y socarrón con el que se anunciaba el periódico. En el caso concreto de El Rizón, Sandra Schlumpf señalaba lo siguiente:

Si bien una parte de las contribuciones y sobre todo el diseño de El Riśón son propios de una revista humorística, entre sus páginas también se hallan artículos cuyos objetivos no son, en primera instancia, entretener a los lectores sino, primordialmente, plantear críticas morales sobre cuestiones actuales (Schlumpf 2010: 191).

Son bastantes las publicaciones sefardíes de este tipo que no solo incluyeron entre sus páginas contenidos graciosos y chistosos, sino que muchas veces se insertaron también escritos de tono más serio, llegándose a publicar graves artículos de denuncia social si era pertinente en aquellos momentos. ${ }^{33}$

\section{Conclusiones}

Como habíamos señaladoal principio, lasfábulas no tuvieron una amplia difusión entre los cuentos populares sefardíes. Las anécdotas atribuidas o protagonizadas por animales eran bastante escasas dentro del repertorio de apólogos y relatos en judeoespañol. Parece que el mayor número de fábulas judaicas se encuentra en la literatura talmúdica y midráshica, y en las colecciones judías medievales europeas, pero, como señalamos, no fue frecuente en el corpus de literatura tradicional y popular en judeoespañol. ${ }^{34}$ Por lo tanto, todo parece indicar que la inclusión de fábulas en los

32 Félix M. Samaniego, Fábulas..., p. 165, n. 6.

33 Remitimos, de nuevo, a María Sánchez-Pérez, Prensa sefardí...

34 Una visión general sobre la fábula en el judaísmo puede verse en la Encyclopaedia Judaica. Disponible en: http://go.galegroup.com/ps/retrieve.do?sgHitCountType=None\&inPS=true\&prodId=GVRL\&us erGroupName=imcpl1111\&resultListType=RELATED_DOCUMENT\&contentSegment $=978002866097$ 4\&isBOBIndex=true\&docId=GALE $\mid$ CX2587506225\#666 [consultado el 12-04-2015]. 
periódicos sefardíes que acabamos de ver, responde a unos criterios bastante claros por parte de los directores y responsables de estas publicaciones:

1. Hay que tener en cuenta que la influencia de la Haskalá -movimiento filosófico judío inspirado en la Ilustración, nacido en el siglo XVIII-, que abogaba por el desarrollo y la integración de los judíos en la cultura occidental, penetró en las comunidades sefardíes de oriente en el siglo XIX. A ello hay qua añadir el importante papel que llevaron a cabo los nuevos sistemas educativos que fueron estableciéndose en el imperio otomano, en especial, la implantación de la red de escuelas que realizó la Alliance Israélite Universelle desde mediados del siglo XIX en diferentes ciudades del mundo. De este modo, el laicismo y la modernización a la manera occidental fueron calando en determinados sectores de las comunidades sefardíes. Además, la influencia del establecimiento de las escuelas francesas de la Alliance descubrió y proporcionó a los sefardíes -entre otras muchas cosas- toda la literatura escrita en francés; de ahí que, a partir de mediados del siglo XIX se tradujesen numerosas obras de este idioma. ${ }^{35}$

2. Parece que podemos deducir, entonces, que la larga tradición de la fábula esópica penetró en el mundo sefardí de la mano del fabulista francés La Fontaine, ya fuese mediante traducciones, adaptaciones o refundiciones de su obra, tal y como hemos ido viendo a lo largo de estas páginas. Por lo tanto, al igual que ocurrió con la novela, no parece que conociesen las adaptaciones y versiones del español, como las de Samaniego, por ejemplo.

3. Desconocemos por qué en el corpus de cuentos populares y tradiciones sefardíes no abundan las fábulas y en las colecciones que se han hecho en los últimos años observamos cómo hay escasez de textos de esta índole ${ }^{36}$. Nos referimos insistimos- a cuentos folclóricos sefardíes de carácter popular y que se transmitieron de

35 Así ocurrió, por ejemplo, con las novelas: «de los aproximadamente trescientos títulos catalogados hasta la fecha, no llegan a un 50 por 100 las novelas de auténtica creación sefardí. Abundan más los textos 'imitados', 'adaptados', 'aranjados' ('arreglados'), 'reśumidos', 'reescritos' y, sobre todo, 'treśladados` (‘traducidos`) por autores sefardíes al judeoespañol a partir de originales en otras lenguas. ¿Qué lenguas eran ésas? [...] la mayor parte son adaptaciones de obras hebreas y francesas [...] destaca el total desconocimiento de la novela española», en Paloma Díaz-Mas, Los sefardíes..., p. 199-200.

36 Sobre los cuentos populares sefardíes del imperio otomano existen varias antologías de Matilda Koen-Sarano Kuentos del folklor de la famiya djudeo-espanyola, Jerusalén, Kana, 1986; Djoha ke dize? Kuentos populares djudeo-espanyoles, Jerusalén, Kana, 1991; Konsejas i konsejikas del mundo djudeo-espanyol, Jerusalén, Kana, 1994; De Saragosa a Yerushaláyim. Kuentos sefaradís, Zaragoza, IberCaja, 1995; Lejendas i kuentos morales de la tradisión djudeo-espanyola, Jerusalén, Kana, 1999; Kuentos salados djudeo-espanyoles, Valencia: Edisiones Capitelum, 2000. Una antología del cuento folclórico sefardí del norte de Marruecos en Arcadio de Larrea Palacín, Cuentos populares sefardies de los judíos del norte de Marruecos, Tetuán, Instituto General Franco, 2 vols., 1952-1953. Un estudio junto con una antología del cuento folklórico sefardí en Tamar Alexander-Frizer, The Heart is a Mirror. The Sephardic Folktale, Detroit, Wayne State University Press, 2008. Y como catálogo fundamental del cuento folklórico sefardí Reginetta Haboucha, Types and Motifs of the Judeo-Spanish Folktales, New York y London, Garland, 1992. 
forma fundamentalmente oral durante generaciones. El hecho, por tanto de que tanto Fresko como Haleví y Asael decidieran incluir entre las páginas de sus publicaciones fábulas como las que hemos visto tiene fácil explicación y parece deberse a que los tres responsables principales de estos periódicos, aunque con ideas, en ocasiones, contrarias, ayudaron a la regeneración moral y material de sus correligionarios mediante, entre otras cosas, la difusión de determinados contenidos entre las páginas de sus publicaciones. Cobra, de este modo, pleno sentido la inclusión de fábulas en los periódicos que hemos visto. Su aparición en ellos no hace sino abundar en la idea de que lo que se vislumbra al analizar todas esas manifestaciones de la cultura tradicional -cuentos, refranes, acertijos, etc.- es que los editores de esta prensa sefardí pretendían ofrecer a su público unos contenidos que eran, al mismo tiempo, entretenidos e instructivos, ayudando así al desarrollo y a la regeneración de sus comunidades.

\section{GLOSARIO}

abasho 'abajo'; abashar 'bajar, descender'; abokar 'inclinar la cabeza'; aferar 'coger, aferrar, atrapar'; agora 'ahora'; akeya 'aquella'; anyo 'año'; ariva 'arriba'; aroiko 'arrollo pequeño'; asolapar 'desierto, vacío'; astusiozo 'astuto'; atinar 'ver'; aver (hb. avir) 'aire, atmósfera, viento'; chichigalia 'cigarra'; chío 'chillido'; degolyar 'degollar'; demandera 'el que pide, exige'; desplazer 'desagradar'; detengash 'detengáis'; djornal (it. gionale, fr. journal) 'periódico'; djugetonas 'juguetonas'; djusto 'justo'; dunke (it, dunque) 'pues, por consiguiente, por tanto, en consecuencia'; elevos (fr. élève) 'alumnos'; emprestadera 'prestadora'; endagora 'ahora, hace un momento'; englenear (tc. eğlenmek) 'divertir, distraer'; engrandeser 'crecer, criar a los hijos'; enigmas 'enigma, adivinanza'; enkolgado 'colgado'; enverano 'verano'; eskaso 'avaro'; eskolas 'escuelas'; espetos 'espetón, barra de hierro para asar las viandas o el pescado'; eyos 'ellos'; Ezop 'Esopo'; famiya 'familia'; farina 'harina'; formiga 'hormiga'; fransez 'francés'; gaina 'gallina'; gainero 'gallinero'; gizandera 'cocinera' ; guadrar 'guardar, defender'; gueler 'oler'; harvar 'pegar, golpear, fustigar'; hazinidades 'enfermedades'; ijikos 'hijicos'; imortal 'inmortal'; kadavre 'cadáver'; kale 'es necesario, hay que, hace falta, es indispensable'; kanyo 'charca de agua con fango, aguas fétidas'; karisar 'acariciar'; kasar 'cazar'; kavesa 'cabeza'; kodreriko 'corderito'; kodrero 'cordero'; konsakradas (fr. consacrer) 'dedicadas'; konseja 'cuento'; korer 'correr'; kriaturas 'hijos, niños pequeños'; kuchio 'cuchillo'; kurto 'corto' (en 'en resumen'); latidas 'pulsaciones, latidos del corazón'; leshos 'lejos'; maimona 'mona'; mankar (fr. manquer, it. mancare) 'faltar, carecer'; maravías 'maravillas'; modrer 'morder'; mos 'nos'; move 'mueve'; muestras 'nuestras'; neshgueliko 'pobrecito'; ofrir (fr. offrir) 'ofrecer, regalar'; oi 'hoy'; olyr 'oír'; propisa 'propicia'; proz 'prosa'; ralos 'raros, escasos'; rakontar 'narrar, contar'; reseftas 'recetas'; rizón 'persona dispuesta siempre a reír'; romanso (it. romanzo) 'novela larga'; savrozos 'sabrosos, graciosos'; selozo 'celoso'; 
shaká (tc. şaka) 'burla, broma, humor'; shara 'bosque, jungla'; sharadas acertijo en que se trata de adivinar una palabra, haciendo una indicación sobre su significado y el de las palabras que resultan tomando una o varias sílabas de aquella; sivdades 'ciudades'; supeto 'de repente'; tiera 'tierra'; topar 'encontrar'; trezladar 'traducir'; trezoro 'tesoro'; turvar 'enturbiar'.

\section{BibLIOGRAFía}

Alexander-Frizer, TAmar, The Heart is a Mirror. The Sephardic Folktale, Detroit, Wayne State University Press, 2008.

Ayala, Amor, «'La instruksión es el más ermozo afeite por la mujer'. Una conferencia de David Fresco sobre la nueva mujer sefardí (Estambul, 1929)», Sefárdica, 17 (2008), pp. 144-155.

BÜRKI, YvetTe, «La Época y El Avenir. Dos periódicos: dos discursos en contraste», en Paloma Díaz-Mas y María Sánchez-Pérez, eds., Los sefardíes ante los retos del mundo contemporáneo. Identidad y mentalidades, Madrid, CSIC, 2010, pp. 159-170. CAMARENA, Julio, «Cuento español, cuento sefardí: paseo entre dos mundos», en Judith Targarona y Ángel Sáenz-Badillos, eds., Jewish Studies at the Turn of the 20th Century, Leiden, Boston y Colonia, Brill, 1999, vol. II, pp. 485-490.

Díaz-Mas, Paloma, Los sefardies. Historia, lengua y cultura, Barcelona, Riopiedras 2006. Fábulas. Fedro y Aviano, Manuel Mañas Núñez, ed., Madrid, Akal/clásica, 1998.

García MoReno, Aitor, «Glosas frescas en La hermośa Hulda de España (Jerusalén, 1910)», en Paloma Díaz-Mas y María Sánchez-Pérez, eds., Los sefardíes ante los retos del mundo contemporáneo. Identidad y mentalidades, Madrid, CSIC, 2010, pp. 75-85.

Haboucha, Reginetta, Types and Motifs of the Judeo-Spanish Folktales, New York y London, Garland, 1992.

Hassán, IАсов M., «El estudio del periodismo sefardí», Sefarad 26, 1966, pp. 229-235.

Koen-Sarano, Matilda, Kuentos del folklor de la famiya djudeo-espanyola, Jerusalén, Kana, 1986.

, Djoha ke dize? Kuentos populares djudeo-espanyoles, Jerusalén, Kana, 1991. , Konsejas i konsejikas del mundo djudeo-espanyol, Jerusalén, Kana, 1994. , De Saragosa a Yerushaláyim. Kuentos sefaradís, Zaragoza, IberCaja, 1995. , Lejendas $i$ kuentos morales de la tradisión djudeo-espanyola, Jerusalén, Kana, 1999. , Kuentos salados djudeo-espanyoles, Valencia: Edisiones Capitelum, 2000.

Larrea Palacín, Arcadio de, Cuentos populares sefardíes de los judios del norte de Marruecos, Tetuán, Instituto General Franco, 2 vols., 1952-1953.

Martínez-Gálvez, Cristina, El periodismo sefardí ante su público. Tesis Doctoral. Universidad de Valencia, 2012. Disponible en http://roderic.uv.es/ handle/10550/24872 [23-11-2015]. 
Martínez-Gálvez, Cristina y María SÁnchez-Pérez (2015), «Adaptación al medio: cambios de proyectos iniciales en la prensa sefardí otomana», Historia y comunicación social 20, pp. 67-87.

Rodrigue, Aron, y Sarah Abrevaya Stein, A Jewish Voice from Ottoman Salonica: The Ladino Memoir of Sa'adi Besalel a-Levi, Standford, Standford University Press, 2012.

Rodríguez Adrados, Francisco, Historia de la fábula clásica, 3 tomos, 4 vols., Madrid, Universidad Complutense, 1979-1987.

Rojas, Fernando de, La Celestina, edición de Peter E. Russel, Madrid, Castalia, 1993.

Romero, Elena, La creación literaria en lengua sefardi, Madrid, MAPFRE, 1992.

SAmAniego, Félix M., Fábulas, Alfonso I. Sotelo, ed., Madrid, Cátedra, 2003.

SÁNCHEZ-PÉREZ, MARÍA, «Tradición y modernidad: la fábula La rapoza se va al hadjilik en el periódico sefardí El Konsejero (Salónica, 1913)», Estudios Humanísticos. Filología, 35 (2013), pp. 109-120.

, Prensa sefardí de pasatiempo en Salónica: un «Konsejero» (1913) y dos «Martíos» (1914 y 1927), Barcelona, Tirocinio, 2014.

SCHLUMPF, SANDRA, «Tradición judía y actualidad social en cuatro artículos publicados en El Riśón de Salónica», en Paloma Díaz-Mas y María Sánchez-Pérez, eds., Los sefardies ante los retos del mundo contemporáneo. Identidad y mentalidades, Madrid, CSIC, 2010, pp. 183-192.

Studemund-Halévy, Michael, y Gaëlle Collin, «The Wondrous Story of Diego de Aguilar», en Michael Studemund-Halévy, Christian Liebl e Ivana Vučina Simović, eds., Sefarad an der Donau. Lengua y literatura de los sefardies en tierras de los Habsburgo, Barcelona, Tirocinio, 2013, pp. 239-247.

Thomas de Antonio, Clara M. ${ }^{\mathrm{a}}$, «Ŷ̀uhā, un personaje popular en el Magreb y en todo el mundo árabe», Al-Andalus Magreb 1 (1993), pp. 187-223. 